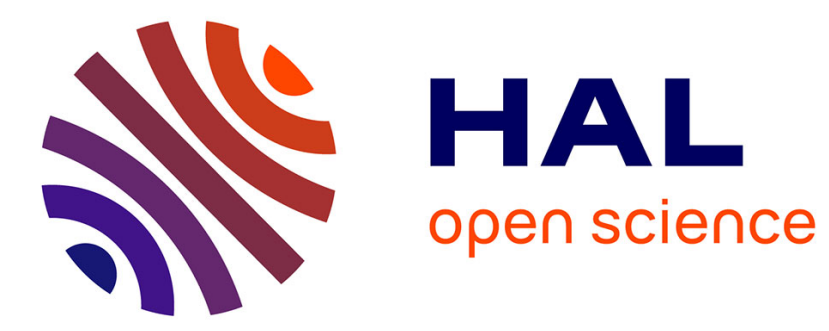

\title{
On the determination of the effective channel length of MOSFETS
}

\author{
N. Patel, M. Garcia, S. Titcomb, R. Anderson
}

\section{To cite this version:}

N. Patel, M. Garcia, S. Titcomb, R. Anderson. On the determination of the effective channel length of MOSFETS. Journal de Physique IV Proceedings, 1994, 04 (C6), pp.C6-25-C6-29. 10.1051/jp4:1994604 . jpa-00253098

\section{HAL Id: jpa-00253098 https://hal.science/jpa-00253098}

Submitted on 1 Jan 1994

HAL is a multi-disciplinary open access archive for the deposit and dissemination of scientific research documents, whether they are published or not. The documents may come from teaching and research institutions in France or abroad, or from public or private research centers.
L'archive ouverte pluridisciplinaire HAL, est destinée au dépôt et à la diffusion de documents scientifiques de niveau recherche, publiés ou non, émanant des établissements d'enseignement et de recherche français ou étrangers, des laboratoires publics ou privés. 


\title{
On the determination of the effective channel length of MOSFETS
}

\author{
N. Patel, M. Garcia*, S. Titcomb and R. Anderson \\ Cryoelectronics Laboratory, University of Vermont, Burlington VT 04505, U.S.A. \\ * Instituto de Ingenieria, Apartodo 40200, Caracas 1040-A, Venezuela
}

\begin{abstract}
The conventional method used to determine $\Delta \mathrm{L}$, the processing induced channel length shortening in MOSFETs at room temperature gives invalid results at $77 \mathrm{~K}$. This error is found to result from the incorrect assumption that the channel resistance is a linear function of effective channel length for the values of gate overdrive normally used for the extraction of $\Delta \mathrm{L}$. By restricting gate voltages to the range where this assumption is shown experimentally to be valid, values of $\Delta \mathrm{L}$ extracted at $77 \mathrm{~K}$ are smaller than those extracted at room temperature. This attributed to the reduced source-channel and drain-channel depletion region widths at $77 \mathrm{~K}$ at and above threshold.
\end{abstract}

\section{INTRODUCTION}

While procedures have been developed to measure $\Delta \mathrm{L}$, the difference between the drawn or mask length $L_{m}$ and the effective channel length $L$ at room temperature, at $77 \mathrm{~K}$ the data are scattered, often with a negative $\Delta \mathrm{L}$ extracted. This result is physically unreasonable since it implies that $\mathrm{L}$ is greater than $\mathrm{L}_{\mathrm{m}}$ The value of $\Delta L$ is extracted from a comparison of measurements with the expression for channel current $I_{D}$, which is assumed to be valid in the limit of small drain-source voltage $V_{D}$ (linear region) for $V_{G}$ $>\mathrm{V}_{\mathrm{T}}+\mathrm{V}_{\mathrm{D}} / 2$

$$
I_{D}=\frac{W C_{o x} \mu_{b f}}{L}\left(V_{G}-V_{T}-\frac{V_{D}}{2}\right)\left(V_{D}-I_{D} R_{T}\right)
$$

where $\mathrm{W}$ is channel width, $\mathrm{C}_{\mathrm{ox}}$ is gate oxide capacitance per unit area $\mu_{\mathrm{If}}$ is average channel carrier mobility at low channel fields, $L$ is channel length, $V_{G}$ is gate-source voltage, $V_{T}$ is threshold voltage and $R_{T}=R_{S}+R_{D}$, with $R_{S}$ assumed equal to $R_{D}$ as expected from symmetry.

From (1) the total device resistance $R_{m}=V_{D} / I_{D}$ for a device of mask length $L_{m}$ can be written.

$$
R_{m}=R_{T}+\mathscr{P}\left(L_{m}-\Delta L\right)
$$


where for a given (small) $V_{D}$,

$$
\mathscr{F}=\left[W C_{o x} \mu_{b^{S}}\left(V_{G}-V_{T}-\frac{V_{D}}{2}\right)\right]^{-1}
$$

with $\mathrm{W}, \mathrm{C}_{\mathrm{ox}}$ and $\mu_{1 \mathrm{f}}$ assumed to be independent of channel length. The dependence of $\mathrm{V}_{\mathrm{T}}$ on $\mathrm{L}$ is taken into account by measuring the threshold voltage for each device. The function $\mathscr{F}$ then for a fixed $V_{D}$ is assumed to be independent of $L$ and a function of only gate overdrive $\left(V_{G}-V_{T}\right)$.

To determine $\mathrm{R}_{\mathrm{T}}$ and $\Delta \mathrm{L}$, which are assumed to be independent of $\mathrm{L}_{\mathrm{m}}$ for a given technology, plots of $R_{m}$ as functions of $\dot{L}_{m}$ for constant $W$ and $V_{D}$ are made for given values of $\left(V_{G}-V_{T}\right)$, well above threshold (to reduce any errors in the extraction of $V_{T}$.) We see then from (2), that these plots are expected to be straight lines that intersect at $\mathrm{R}_{\mathrm{m}}=\mathrm{R}_{\mathrm{T}}$ and $\mathrm{L}_{\mathrm{m}}=\Delta \mathrm{L},[1-3]$. This method, appears to give reliable values of $R_{T}$ and $\Delta L$ at room temperature for devices with channel lengths greater than about one $\mu \mathrm{m}$. At low temperatures, however, the $R_{m}-L_{m}$ plots do not intersect at a single point. If an average value of the intersections is taken, the value of $\Delta \mathrm{L}$ extracted is often negative, implying that the actual channel length is greater than the mask length [4,5], a result that is difficult to explain physically. In this paper we refer to the above technique to determine $\Delta \mathrm{L}$ and $\mathrm{R}_{\mathrm{T}}$ as the conventional method.

It has been suggested that the failure of the conventional method at $77 \mathrm{~K}$ results from an inaccuracy in the determination of $\mathrm{V}_{\mathrm{T}}$ by the maximum slope method [6]. The error is thought to result from the large dependence of $\mu_{\mathrm{lf}}$ on $V_{G}$ and the relatively large influence of $R_{T}$ on the $I_{D}-V_{G}$ curves. To overcome this potential problem, a shift and ratio (S\&R) method was developed [5]. If $R_{T}$ is independent of $V_{G}$, taking the derivative of (3) with respect to $V_{G}$ gives for a device $i$

$$
S_{i}=\frac{\partial R_{m i}}{\partial V_{G}}=0+\frac{\partial \mathscr{F}}{\partial V_{G}}\left(L_{m i}-\Delta L\right)
$$

where $\partial \mathscr{F} / \partial \mathrm{V}_{\mathrm{G}}$ is a general function of gate overdrive common to all devices on the test chip. Using a long channel device as reference such that $\mathrm{L}_{\mathrm{mo}}$ » $\Delta \mathrm{L}, \mathrm{S}_{\mathrm{i}}$ can be shifted in $\mathrm{V}_{\mathrm{G}}$ (to compensate for the difference in $\mathrm{V}_{\mathrm{T}}$ ) until the ratio of $\mathrm{S}_{\mathrm{i}} / \mathrm{S}_{\mathrm{o}}$ is constant. Here $\mathrm{S}_{\mathrm{o}}$ and $\mathrm{L}_{\mathrm{mo}}$ refer to the reference device. Then from (5) $\Delta \mathrm{L}$ is obtained

$$
\Delta L=L_{m i}-L_{m o}\left(\frac{S_{i}}{S_{0}}\right)
$$

We have modified the S\&R method such that a long channel reference device, while convenient, is not required. We also plot the data somewhat differently such that a better physical insight can be obtained, especially in the region well above threshold where the conventional method is used Plots of $S_{i}$ are moved horizontally and vertically with respect to $S_{0}$ until $S_{i}$ and $S_{o}$ coincide. The horizontal displacement is then equal to the difference in $V_{T}$ of the two devices while the vertical displacement (log scale) gives the ratio of $S_{\gamma} / S_{0}$. Then for coincidence,

$$
\frac{S_{i}}{S_{o}}=\frac{L_{m i}-\Delta L}{L_{m o}-\Delta L}
$$

For a given reference device, $\left(\mathrm{L}_{\mathrm{mo}}-\Delta \mathrm{L}\right)$ is a constant and a plot of $\mathrm{S}_{/} / \mathrm{S}_{\mathrm{o}}$ against $\mathrm{L}_{\mathrm{mi}}$ gives a straight line. Extrapolating to $S_{i} / S_{0}=0$ gives $L_{m i}=\Delta L$. These results are then checked by plotting $\left(L_{m o}-\Delta L\right) S / S_{0}$ vs. $\mathrm{L}_{\mathrm{mi}}$ to verify that the slope of this graph is a straight line of unity slope as expected (Eq. 6). 


\section{EXPERIMENT}

The devices used in this study were fabricated with CMOS technology for room temperature operation. The average net doping in the channel region is about $10^{17} \mathrm{~cm}^{-3}$. The source and drain junctions are abrupt (non-LDD) and thus the variation of $R_{T}$ on $V_{G}$ is expected to be negligible. The gate material is $\mathrm{n}^{+}$polysilicon which results in "buried channel" PFETs. Because of the freezeout of channel holes onto the acceptors implanted for threshold control, the electrical characteristics are not given by (1) at $77 \mathrm{~K}$. Thus only NFETs are discussed here. In this work devices with mask width of $20 \mu \mathrm{m}$ were used. Mask channel lengths of $0.6 \mu \mathrm{m}$ to $20 \mu \mathrm{m}$ were tested and nominal gate oxide thickness is $15 \mathrm{~mm}$.

Data were taken at room temperature and at $77 \mathrm{~K}$ (immersed in liquid nitrogen) with the aid of a computer-controlled Hewlett Packard Transistor Parameter Analyzer model 4145A. Plots of $S_{i} v_{s} V_{G}$ were made using similar vertical scales (decades $/ \mathrm{cm}$ ) and horizontal scales $(\mathrm{V} / \mathrm{cm}$ ) such that they could be moved horizontally and vertically with respect to each other to obtain coincidence.

\section{RESULTS}

Figure 1 shows the room temperature $S_{i}$ data as a function of $V_{G}$ shifted to obtain coincidence for the longest $\left(\mathrm{L}_{\mathrm{m}}=20 \mu \mathrm{m}\right)$ and shortest $\left(\mathrm{L}_{\mathrm{m}}=0.6 \mu \mathrm{m}\right) \mathrm{n}$-channel devices. Reasonable coincidence occurs for the range of $\mathrm{V}_{\mathrm{G}}$ from about $0.4 \mathrm{~V}$ above threshold to about $5 \mathrm{~V}$. . The range of coincidence extends to lower values of $V_{G}$ as the channel lengths approach each other.

Similar plots are shown for these same NFETs at $77 \mathrm{~K}$ in Figs. 2.. We can see that coincidence is obtained from just below threshold to about $1.1 \mathrm{~V}$ above threshold. We can also see that with increasing gate overdrive the deviation from coincidence becomes larger.

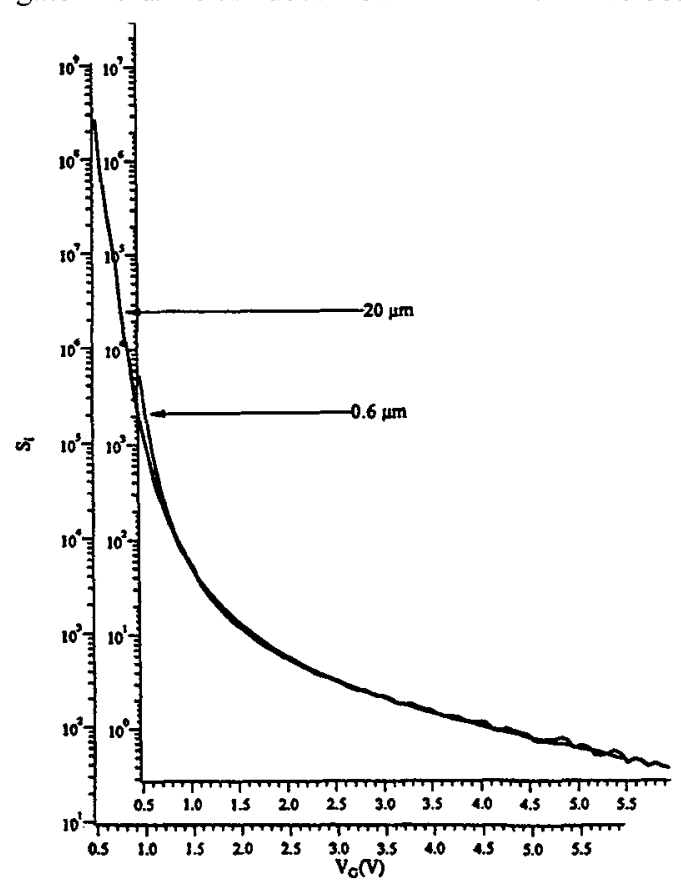

Fig. 1. Plot of $S_{i}$ as functions of $V_{G}$ for $n-$ channel devices with mask lengths of 0.6 and $20 \mu \mathrm{m}$ : The plots are shifted horizontally and vertically to obtain coincidence.

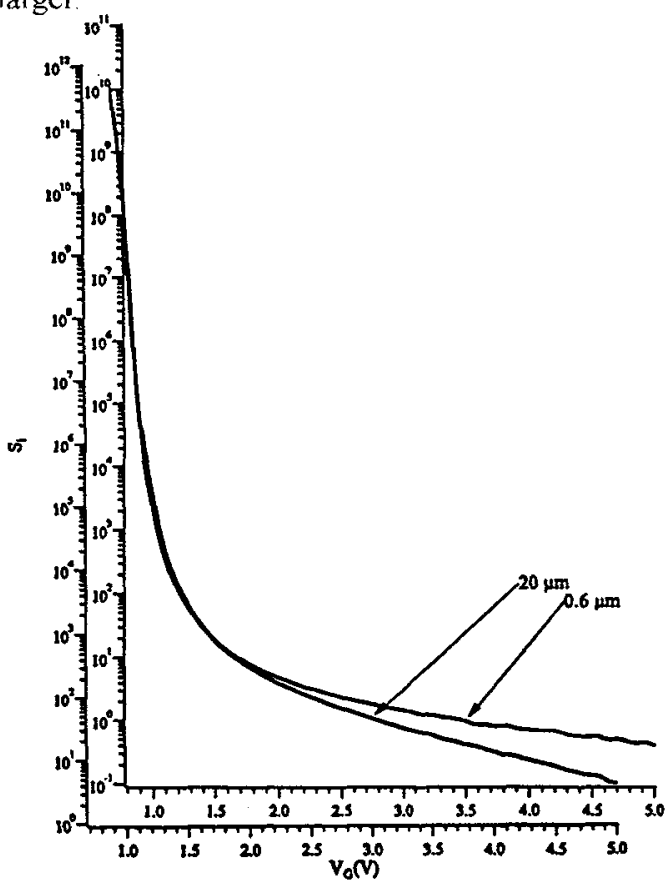

Fig. 2 Plots $S_{i}$ vs. $V_{G}$ at $77 \mathrm{~K}$ for the devices of Fig. 1.

A plot of $\mathrm{S}_{\mathrm{i}} / \mathrm{S}_{\mathrm{o}}$ for $\mathrm{n}$-channel devices in the region of coincidence using the $20 \mu \mathrm{m}$ device as 
reference is plotted in Fig. 3 for room temperature. A least-square fit to a straight line gives $\Delta \mathrm{L}=0.36 \mathrm{~V}$. This is close to the value of $0.32 \mathrm{~V}$ obtained by the conventional method.

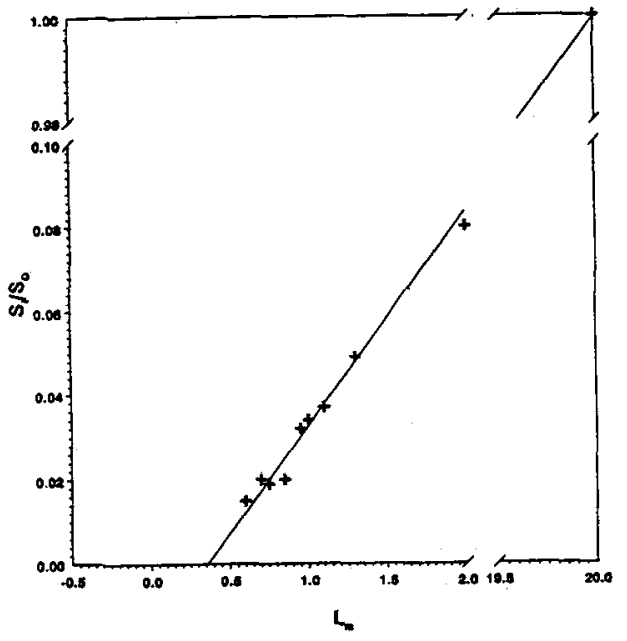

Fig. 3. Plot of $\mathrm{S}_{\mathrm{i}} / \mathrm{S}_{\mathrm{o}}$ vs. $\mathrm{L}_{\mathrm{m}}$ with $\mathrm{L}_{\mathrm{m}}=20 \mu \mathrm{m}$ as reference. The $L_{m}$ intercept is the extracted value of $\Delta \mathrm{L}$.

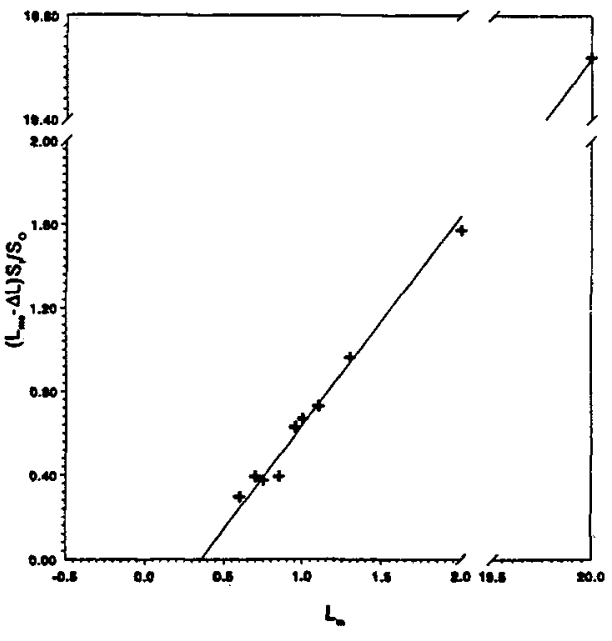

Fig. 4. Plot of $\left(L_{m o}-\Delta L\right) S_{j} / S_{o}$ vs. $L_{m}$ for room temperature. The $\mathrm{L}_{\mathrm{m}}$ intercept indicates $\Delta \mathrm{L}$. The slope is near-unity as expected.

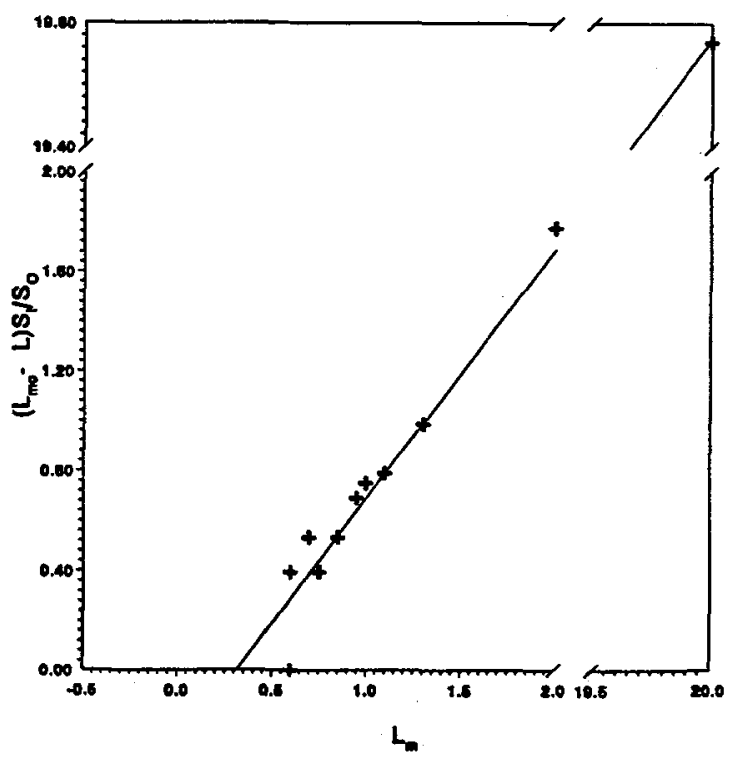

Fig. 5. Plot of $\left(L_{m o}-\Delta L\right) S_{i} / S_{o}$ vs. $L_{m}$ for 77 $\mathrm{K}$. As for room temperature, the $\mathrm{L}_{\mathrm{m}}$ intercept yields $\Delta \mathrm{L}$ and the slope is close to unity. 
Figure 4 shows the room temperature plot of $\left(L_{m o}-\Delta L\right) S_{j} / S_{o}$ as a function of $L_{m}$. The slope is 1.01 , close to the expected value of unity. A similar plot at $77 \mathrm{~K}$ is shown in Fig. 5 yielding $\Delta \mathrm{L}=0.32 \mu \mathrm{m}$ and a slope within one percent of unity. We note that this value is $0.04 \mathrm{~V}$ less than at room temperature. We also note that the conventional method for this case did not give meaningful results because the plots of $R_{m}$ vs. $L_{m}$ for different gate overdrive of $1,2,3$, and $4 \mathrm{~V}$ did not intersect at believable values of $R_{T}$ and $\Delta \mathrm{L}$.

\section{DISCUSSION AND CONCLUSIONS}

Both the conventional and S\&R methods of $\Delta \mathrm{L}$ extraction depend on the function $\mathscr{F}$ and thus $\partial \mathscr{F} / \partial \mathrm{V}_{\mathrm{G}}$ ) being a general function of gate overdrive common to all devices of a given technology and independent of channel length, and $R_{T}$ being independent of gate voltage. These assumptions are clearly valid at room temperature for the devices tested for $V_{G}>V_{T}$ as can be seen from Fig. 1.. Thus both methods are expected to be valid. The values of $\Delta \mathrm{L}$ extracted, 0.36 and $0.32 \mu \mathrm{m}$ respectively for the $\mathrm{S} \& \mathrm{R}$ and conventional methods respectively are within experimental accuracy of each other.

We see then from Fig. 2 however, at $77 \mathrm{~K}$ coincidence can not be obtained for NFET's in the region appreciably above threshold indicating that $\partial \mathscr{F} / \partial \mathrm{V}_{\mathrm{G}}$, and thus $\mathscr{F}$, are not independent of channel length as assumed, at least at these values of $\mathrm{V}_{\mathrm{G}}$. Since the conventional method relies on data from this range of $V_{G}$, it is not surprising that it fails at this temperature. The extracted value of $\Delta \mathrm{L}$ is $0.04 \mu \mathrm{m}$ less at $77 \mathrm{~K}$ than at room temperature. This is in good agreement with the value of $0.045 \mu \mathrm{m}$ calculated considering the reduced source-channel and drain channel depletion regions at and above threshold [ 7].

Both the conventional and shift and ratio methods are valid at room temperature for the measurement of $\Delta \mathrm{L}$. It is found that the failure of the conventional method at $77 \mathrm{~K}$ results from the assumption that the channel resistance per unit channel length is a unique function of overdrive and independent of channel length. This assumption is shown to be incorrect in the region of overdrive voltage which is normally used in this method. The S\&R method is valid at this temperature because it is restricted to gate overdrive values where the above assumption is shown experimentally to be valid.

We acknowledge the support of the Avionics Directorate, Wright Laboratory, Air Force Materiel Command, United States Air Force, Wright-Patterson AFB.

\section{References:}

[1] Ng K. K. and Brews J. R., Circuits and Devices, (1990) pp. 33 - 38.

[2] Terada K. and Muta H., Jap. J. Appl. Phys. 18 (1979) pp. 953-959.

[3] Chern J. G. J. et al, IEEE Electron Device Lett. EDL 1 (1980) pp. 270-274

[4] Garcia M. et al, "Parameter extraction at liquid nitrogen temperature on short channel PMOS devices" Anais da VIII Congresso da Sociedad Brasileira de Microletronica (1993) pp. VI.7-VI-12.

[5] Taur Y. et al, IEEE Electron Devices Lett. 13 (1992) pp. 267-269

[6] Jain S. Proc. Inst. Elec. Eng. 135-1 (1988) pp. 162-

[7] Kamgar A, "Si MOS Devices at Low Temperatures", Proceedings of the Cold Electronics Workshop, Pasadina 4-5 October $1984 \mathrm{pp} 83-91$. 